\title{
SARS-CoV-2 (COVID-19): Zoonotic Origin and Susceptibility of Domestic and Wild Animals
}

\author{
Vinodh Kumar O.R. ${ }^{1 *} \mathbb{D}$, Ramkumar ${ }^{1}$, B.S. Pruthvishree ${ }^{2}$, Tripti Pande ${ }^{3}$, \\ D.K. Sinha ${ }^{1}$, B.R. Singh ${ }^{1}\left(\mathbb{D}\right.$, Kuldeep Dhama ${ }^{4}$ and Yashpal S. Malik ${ }^{3 *}$ (iD \\ ${ }^{1}$ Division of Epidemiology, ICAR-Indian Veterinary Research Institute, Izatnagar, Bareilly - 243 122, Uttar Pradesh, \\ India. ${ }^{2}$ Veterinary Clinical Complex, Veterinary College, Hombal road, Gadag - 582 101, Karnataka, India. ${ }^{3}$ Division \\ of Biological Standardization, ICAR-Indian Veterinary Research Institute, Izatnagar, Bareilly- 243 122, Uttar \\ Pradesh, India. ${ }^{4}$ Division of Pathology, ICAR-Indian Veterinary Research Institute, Izatnagar, Bareilly- 243122, \\ Uttar Pradesh, India.
}

\begin{abstract}
Coronaviruses (CoVs) are responsible for causing economically significant diseases both in animals and humans. The Severe Acute Respiratory Syndrome Coronavirus-2 (SARS-CoV-2), causing Coronavirus Diseases (COVID-19), outbreak has become the first pandemic of the 21st century and is the deadliest pandemic after the 1918 Spanish Flu. Except, the two previous epidemics, SARS-CoV (2002 epidemic, China) and MERS-CoV (2012 epidemic, Middle Eastern region), CoVs are known the world over as the mild pathogens of humans and animals. Despite several measures to control the COVID-19 pandemic, it has affected more than $\mathbf{2 1 0}$ countries and regional territories distressing more than $\mathbf{5 . 3}$ million people and claiming nearly 0.34 million lives globally. Several findings point towards the appearance of the SARS-CoV-2 virus in the humans through animals, especially the wild animals of the Chinese live seafood wet market. The ongoing COVID-19 pandemic is another example of diseases originating from the human-animal interface and spreading through international borders causing global health emergencies. Most of the countries around the globe are stumbling due to the COVID-19 pandemic with severe threats and panic among the mass population. World Health Organization (WHO), international and national health authorities are working with excessive efforts for effective and impactful interventions to contain the virus. It is significant to comprehend the inclination of these viruses to jump between different species, and the establishment of infection in the entirely new host, identification of significant reservoirs of coronaviruses. Several animal species such as cats, dogs, tiger, and minks have been confirmed to get SARS-CoV-2 infections from COVID-19 infected person. Laboratory investigations point out those cats are the most susceptible species for SARS-CoV-2, and it can evidence with clinical disease. The studies carried out on animal's susceptibility to SARS-CoV-2 further support the human-to-animal spread of the virus. In this review, we focus on addressing COVID-19 infections in domestic and wild animals.
\end{abstract}

Keywords: SARS-CoV-2, COVID-19, Tiger, Cat, Domestic Animals, Wild Animals

*Correspondence: vinodhkumar.rajendran@gmail.com; malikyps@gmail.com

(Received: May 07, 2020; accepted: May 19, 2020)

Citation: Kumar VOR, Ramkumar, Pruthvishree BS, Pande T et al. SARS-CoV-2 (COVID-19): Zoonotic Origin and Susceptibility of Domestic and Wild Animals. J Pure Appl Microbiol. 2020;14(suppl 1):741-747. doi: 10.22207/JPAM.14.SPL1.11

(C) The Author(s) 2020. Open Access. This article is distributed under the terms of the Creative Commons Attribution 4.0 International License which permits unrestricted use, sharing, distribution, and reproduction in any medium, provided you give appropriate credit to the original author(s) and the source, provide a link to the Creative Commons license, and indicate if changes were made. 


\section{INTRODUCTION}

Coronaviruses (CoV) are well established source of respiratory illness and intestinal problems in animals and humans, and a few are zoonotic ${ }^{1}$. The spike protein around the lipid envelope of the virus gives a characteristic 'crown' shape to the virion, following to that these are named as coronavirus. The CoV manifestation in humans varies from the mild flu like symptoms to fatal signs as seen during the Severe Acute Respiratory Syndrome (SARS) and Middle East Respiratory Syndrome, MERS outbreaks in humans².

The coronavirus disease (COVID-19) with severe pneumonic symptoms has emerged in Wuhan city, China and the World Health Organization (WHO) declared the COVID-19 as a public health emergency of international concern on $30^{\text {th }}$ January 2020 due to severe implications of the disease to several other countries including an international conveyance ${ }^{3,4}$. Further, based on the distressing levels of spread and severity, on $11^{\text {th }}$ March 2020, the disease was confirmed by the WHO having pandemic status 5 . The emergence and spread of the virus were associated with seafood Wuhan wet market, Hubei Province, China ${ }^{6}$. Since the reports on SARS in 2002 from China, seveal novel coronaviruses have been documented in animal hosts, with a few appeared to possess a link to human infections ${ }^{7}$. The CoV infects several species of mammals, birds, reptiles, and wildlife ${ }^{8,9}$. A study also proposed snakes as the most likely wildlife reservoir for SARS-CoV-2 and possibly responsible for "cross-species" transmission?. However, later this hypothesis was opposed by many research groups.

\section{Origin of Zoonotic SARS-CoV and SAR-CoV-2}

The SARS-CoV, causing SARS, first documented in 2002 in China and blowout to 29 countries as a global threat in a short time. The SARS emergence demonstrated slow emergence of coronavriruses from animal hosts with possibly fatal diseases in humans ${ }^{10}$. The International Committee on Taxonomy of Viruses (ICTV) renamed the 2019-noCoV as SARS-CoV- ${ }^{2}$.

The origin of SARS-CoV was considered to be from bats, although it needs further evidence to prove as actual host, similarly the palm civet cats from the wet markets of Guangdong China, was supposed to be the intermediate host ${ }^{11}$. The $\mathrm{CoV}$ infected bats usually remain asymptomatic, indicating mutual adaption of both ${ }^{12}$. Another fatal CoV that affected humans, the MERS, is caused by a MERS-CoV, which occur due to contact with camels or camel products and is endemic in Middle East $^{13}$. However, among all CoVs of humans, the ongoing outbreaks due to SARS-CoV-2 have higher virulence and, in a short period caused the global pandemic and created a significant threat to the public health ${ }^{14}$. Its emergence narrates the use of wild animal meat in Wuhan, China ${ }^{15}$. The epidemiological evidence indicates that zoonotic transmission of COVID-19 has occurred in Wuhan's Seafood Wholesale Market through the trade of wild animals. Molecular analysis exhibited that the virus has a higher similarity with a horseshoe bat coronavirus obtained from Yunnan Province ${ }^{16,17}$. Bats viruses can rarely infect humans directly. Hence, there has to be another host involved in virus transmission. The SARS-CoV-2 probability to affect different hosts relies on the receptorbinding domain (RBD) of spike glycoprotein ${ }^{18}$. In a study, RaTG13 genome of bat coronavirus shared only one out of five important amino acids residues that are present in the receptor-binding motif, and the pangolin CoV shared all the five amino acid residues ${ }^{19}$. Recently, more evidence is building giving indication that pangolins could have transmitted infection to humans.

Pangolin skin scales are used as Chinese medicine. The pangolins are trafficked from several regions of the world to the seafood market in China. A study on six genomes from Malyan pangolins in Guangxi denoted GX/P1E, GX/P2V, GX/P3B, GX/P4L, GXP5E, and GX/P5L and two from Guangdong GD/P2S and GD/P1L found 85.5 to $92.4 \%$ sequence homology to SARS-CoV- 2 . The sequences of pangolins from Guangdong were more narrowly connected to SARS-CoV- $2^{20}$. The civets that were associated with the transmission of SARS-CoV have been found distantly related to current transmission as their ACE2 receptors can only recognize SARS-CoV but not SARS-CoV- 2 . This finding out rules the possibility of civets in the transmission as ACE2 binding is a trigger for a cascade of events responsible for virus and cell membrane fusion for cell entry ${ }^{21,22}$. The SARSCoV-2 obtained from the Chinese Wuhan market supports the persistence of the virus through a live animal source; however, the likely SARS-CoV-2 intermediate host could be Rhizomyidae family 
Bamboo rats and civets, but no absolute proof is accessible. The metagenomic profiling of CoVs specifies pangolins to possess Betacoronaviruses ${ }^{23}$. The experimentations have been initiated on several animal species in order to augment the search for potential intermediate hosts. The susceptibility testing on cats, dogs, ferrets, and other domesticated animals reveal ferrets being more susceptible and prone to virus replication in their upper respiratory tract for a period of up to eight days. It also showed susceptibility of cat to droplet infection, low susceptibility of dogs to infection while pigs, chicken, and ducks were not found susceptible ${ }^{24}$. Based on ACE2 receptor residues that interact with $S$ glycoprotein of SARS-CoV-2, turtles that are also frequently trafficked in animal markets were suggested to be potential expanded hosts, however further studies are warranted for claiming such findings ${ }^{25}$. Evolution studies of the RBD domain tell that it is unlikely to infect mice and rats, as the ACE2 receptor contains histidine in 353 positions that do not fit in virus-receptor interaction. However, identical ACE 2 residues were found in pigs, ferrets, orangutans, and monkeys ${ }^{26}$. The possibility of mice and rabbits as intermediate host has been ruled out based on RBD and ACE2 receptor interaction. They hold the least binding affinity to RBD compared to other mammalian hosts ${ }^{27}$. Another study on evolutionary analysis showed that novel coronavirus had similar codon usage bias with a snake, but gave no experimental proof of infection in snakes ${ }^{9}$.

On the contrary, bat coronaviruses that have been found to share RBD domains shared low synonymous codon usage resemblance with SAR-CoV-2. The codon usage of camel and swine has also been found distantly clustered from SAR$\mathrm{CoV}-2^{28}$. Before calling a species as an intermediate host, not only its ability to be infected by a virus by its receptor homology must be considered, but the permissiveness of the host system to harbor it and excrete it for transmission needs to be addressed. Hence, more evidence would be required to identify the intermediate host responsible for zoonotic transmission.

Coronaviruses Infecting Animals

Based on the genetic properties, the Coronaviridae family members are divided into four genera, namely Alphacoronavirus,
Betacoronavirus, Gammacoronavirus, and Deltacoronavirus. The beta-CoV genus comprises most of the Human CoVs and is further divided into 04 lineages namely $A, B, C$, and $D^{29}$. The genera Alphacoronavirus and Betacoronavirus infect bats and other mammals, the Gammacoronavirus and Deltacoronavirus infect mammals, poultry, and fish $^{30,31}$. The CoVs from civet cats and raccoon dogs have been established as SARS-CoV group members ${ }^{32}$. To date, there are seven recognized human CoVs (HCoVs) where HCoV-229E and HCoV$\mathrm{NL63}$ are alpha-CoVs. The other five beta-CoVs are HCOV-OC43, HCOV-HKU1, SARS-COV, MERS-CoV, and SARS-CoV- $2^{33}$. These HCoVs have been linked to possessing zoonotic origin ${ }^{34,35}$.

MERS-CoV, another zoonotic virus of Betacoronavirus, not only infects camelids but viral RNA is also evident in nasal swabs from the donkey, sheep, and goats, having narrow association with camels ${ }^{36,37}$. Bats are found to be reservoirs of alphacoronaviruses and betacoronaviruses, while birds acts as reservoirs for gammacoronaviruses and delatacoronaviruses ${ }^{38,39}$. Compared to SARS-CoV and MERS-CoV, the SARS-CoV-2 is less pathogenic but with higher transmission potential ${ }^{14,40}$. The human-animal interface provides the new ecological niches to the coronaviruses, which leads to evolution and emergence ${ }^{41-43}$. The significant species jump from bats to other mammals is mainly due to the recombination in the Spike gene ${ }^{44}$. One study in Amur hedgehogs supported that hedgehog CoVs could recombine with bat CoVs giving rise to viruses that have the potential for interspecies transmission. It was after finding a novel Betacoronavirus in the hedgehog ${ }^{45}$. According to the Chinese researchers, dogs are not vulnerable to SARS-CoV-2; however, the cats may acquire COVID-19 infection and can spread it to other cats. According to the researchers at Harbin Veterinary Research Institute, the chickens, pigs, and ducks are not likely to catch the virus ${ }^{24}$. Laboratory findings suggest that cats are the most susceptible and can be infected with the clinical disease and were shown to transmit the infection to other cats in the laboratory settings ${ }^{46}$.

\section{Reports of COVID-19 in Animals}

There is limited information available to date, to justify the risk of animals such as dogs and cats spreading COVID-19 to people. In Hong Kong, testing of dogs and cats co-habituated with 
COVID-19 patients revealed that proof of the virus in two dogs: a Pomeranian and a German shepherd without clinical signs ${ }^{47}$. It was likely the first human-to-animal infection of COVID-19, as the owner was suffering from COVID-19, the WHO has unanimously agreed that "it is likely to be a case of human-to-animal transmission" ${ }^{46}$. Subsequently, the second case appeared in a German shepherd dog possessed by COVID-19 patient who was inhome quarantine. Oral and nasal swabs shown positive readings for the German shepherd but were negative for the other dogs tested ${ }^{48}$.

The initial case of human-to-cat transmission of the novel CoV was seen in Belgium. A week after the pet-owner from Belgium was infected with COVID-19, the family cat began showing similar symptoms of the virus- respiratory issues and diarrhea. The authority in the Belgium government called this an "isolated case" which may occur after a close-contact between infected humans with animals. However, they ruled out that animals could be vectors of the pandemic virus. Lately, a tiger at the Bronx Zoo tested positive for the SARS CoV-2, joining the number of other animals around the world infected with COVID-19. The Bronx Zoo's tiger, a 4-year-old Malayan tiger, named Nadia, is the first animal in the USA and the first non-domesticated animal globally to have a confirmed COVID-19 case. Three weeks after the Malayan tiger was tested positive, another 04 tigers and 03 lions were confirmed to carry COVID-19 infection at Bronx Zoo ${ }^{49}$. At least two pets, a cat and a dog were infected in Hong Kong; and a cat in Belgium is also believed to have had the virus infection. People with confirmed
COVID-19 owned all of the pets. In the USA, two pet cats that had mild respiratory illnesses were confimed to have COVID-19 infection ${ }^{50}$.

In a serological survey of domestic livestock and companion animals for SARS-CoV-2 using a double antigen sandwich ELISA, no domestic livestock was detected positive. While the experimentally infected ferret showed strong seropositivity, however, SARS-CoV-2 specific antibodies were not found in dogs and cats of Wuhan city ${ }^{51}$. The chronology of SARS-CoV-2 infection in animals is given in Fig. 1.

Studies are going on to resolve the doubts related to host cellular receptor (ACE2) binding with the virus. Interaction studies based on the computer modeling of RBD and ACE2 receptors found that the cat's binding free energy and critical amino acids responsible for binding are quite similar to humans. But revealing of correct host would require more epidemiological surveillance of affected areas and regions surrounding them. However, unless the right intermediate host is confirmed, the contact with potential intermediate hosts should be prevented. The COVID-19 infection screening for pets is not recommended until these pets get exposed to a COVID-19 confirmed patient, and the animal exhbits COVID-19 clinical signs ${ }^{50}$. Measures while Handling Companion Animals (for COVID-19 Suspected Person's)

At the present scenario, there is no indication for companion animals showing relationship in epidemiology and the spread of COVID-19. However, there are few reports of humans to the animal transmission of COVID-19, so it is recommended that the persons who are

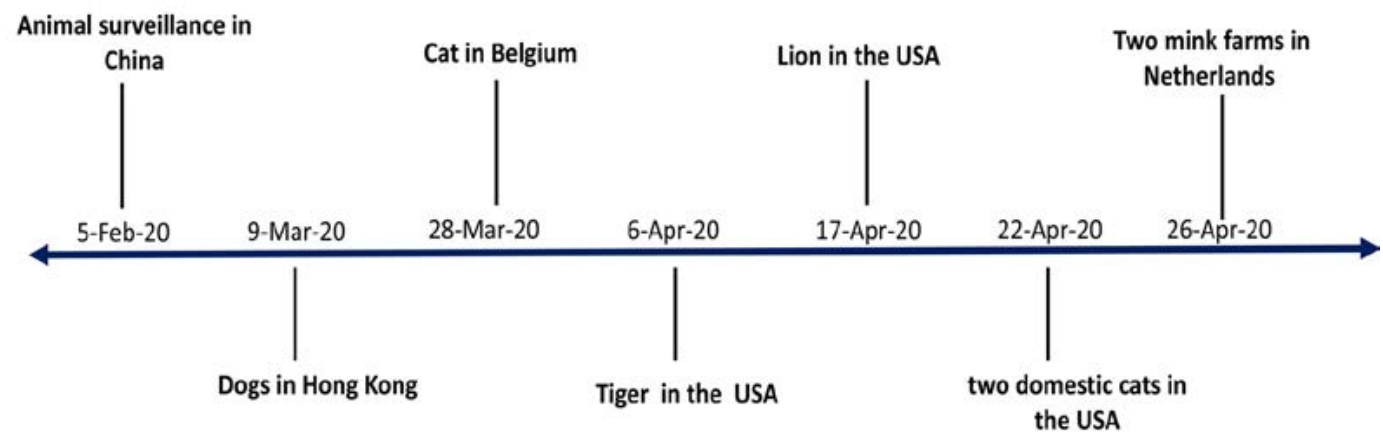

Fig. 1. Timeline of COVID-19 infections in animals 
suspected or affected with COVID-19 should limit the contact with a companion or other animals.

The necessary hygienic measures, while handling and caring for animals, include washing hands while handling or playing with the companion animals and as much as possible avoid licking, kissing the pets, and sharing of food with them. The persons affected by COVID-19 should avoid close contact with their pets and assign another member of their household to take care of their pets. The infected person or owner of pets must look after them unless they maintain good hygiene practices. The animals belonging to COVID-19 infected persons should be kept indoors as much as possible, and contact with other pets must be avoided ${ }^{46}$. One health approach needs to be implemented along with appropriate prevention and control adopted to avoid and counter COVID-1952.

Veterinarian's Role in COVID-19 Prevention

Any symptoms or infections mimicking the SARS-CoV-2 in animals that should be reported to national authorities and further to OIE.

In some countries like India, Veterinary Services are supporting in COVID-19 public health response by testing samples from humans.

Veterinarians should stay focused, informed and continue to be in close liaison with public health officials for the prevention of COVID-19 infections in animals ${ }^{45,53}$.

Role of Geographic Information System (GIS) in COVID-19 pandemic

Geographic information system (GIS) uses computer and other information technology for analyzing a spatial patterns of trends ${ }^{54}$. In disease surveillance and monitoring, it integrates outbreak location and the population at risk. In the recent COVID- 19 outbreak, GIS is extensively used to contain the outbreak. The geo-mapping of the COVID -19 positive cases allows identifying the high-risk zones and hot spots. In humans, the GIS application can be efficiently used to prevent, and control of Covid-19 spread. Many countries use mobile GIS applications, GPS records of cars, and cellphones to track the contacts of the first case. In the COVID-19 situation, satellite-based and aerial photography are efficiently used for surveillance. The drone-based aerial photography has gained importance during lockdown to monitor the public movement. Additionally, the use of GIS-based surveillance technologies is indispensable in the ongoing COVID-19 crisis.

\section{CONCLUSION}

Nowadays, zoonotic infections in humans are on increase requiring timley preparedness as the global health agenda. The pandemic outbreak in Wuhan Province, China, is a clear message of the zoonotic threats to the global health agencies. The collaborative global effort, such as "One-Human-Environmental-Animal Health" is required to diminish the international risk of zoonotic diseases. Health authorities and scientists representing different professional streams must work collectively to minimize the impact of zoonotic infectious diseases at different levels. The "One-Health" approach aims to break down the barriers between the researchers from humans, animals, and ecosystems bring alltogether to accomplish optimum well-being of humans, animals, and the environment. Recent technologies like GIS and drone photography could be efficiently used in mitigating Covid-19 pandemic.

\section{ACKNOWLEDGMENTS}

All the authors acknowledge and thank their respective Institutes and Universities. YSM acknowledges the Education Division, ICAR, Gol for National Fellowship. Mobile based Arogya-Setu App launched by Government of India is the best example of use of GIS technology and is proving its utility in containment of COVID-19.

\section{CONFLICTS OF INTEREST}

The authors declares that there is no conflict of interest.

\section{AUTHORS' CONTRIBUTION}

All the authors substantially contributed to the conception, compilation of the review, checking and approving the final version of the manuscript, and agree to be accountable for its contents.

\section{FUNDING}

None. 


\section{ETHICS STATEMENT}

This article does not contain any studies with human participants or animals performed by any of the authors.

\section{DATA AVAILABILITY}

All datasets generated or analyzed during this study are included in the manuscript and/or the Supplementary Files

\section{REFERENCES}

1. Masters PS, Perlman S. Coronaviridae. Fields Virology. 2013;1:825-58.

2. WHO. Questions and Answers on the 2019 Coronavirus Disease (COVID-19) https://www.oie. int/scientific-expertise/specific-information-andrecommendations/questions- and- answers-on2019novel-coronavirus/ accessed on 1st May, 2020.

3. Cortegiani A, Ingoglia G, Ippolito M, Giarratano A, Einav S. A systematic review on the efficacy and safety of chloroquine for the treatment of COVID-19. J Crit Care. 2020. https://doi.org/10.1016/j.jcrc.2020.03.005

4. Zhu N, Zhang D, Wang W, et al. A novel coronavirus from patients with pneumonia in China, 2019. N Eng J Med. 2020.

5. Bedford J, Enria D, Giesecke J, et al. COVID-19: towards controlling of a pandemic. The Lancet. 2020;395(10229):1015-8. https://doi.org/10.1016/ S0140-6736(20)30673-5

6. Rothan HA, Byrareddy SN. The epidemiology and pathogenesis of coronavirus disease (COVID-19) outbreak. J Autoimmun. 2020;102433. https://doi. org/10.1016/j.jaut.2020.102433

7. Anderson LJ, Tong S. Update on SARS research and other possibly zoonotic coronaviruses. Int J Antimicrob Agents. 2010;36:S21-5. https://doi.org/10.1016/j. ijantimicag.2010.06.016

8. Kim YI, Kim SG, Kim SM, et al. Infection and rapid transmission of sars-cov-2 in ferrets. Cell Host Microbe. 2020. https://doi.org/10.1016/j.chom.2020.03.023

9. Ji W, Wang W, Zhao X, Zai J, Li X. Homologous recombination within the spike glycoprotein of the newly identified coronavirus may boost cross-species transmission from snake to human. J Med Virol. 2020. https://doi.org/10.1002/jmv.26048

10. Saif LJ. Animal coronaviruses: what can they teach us about the severe acute respiratory syndrome?. Revue scientifique et technique-Office international des epizooties. 2004;23(2):643-660. https://doi. org/10.20506/rst.23.2.1513

11. Hui DS, Zumla A. Severe Acute Respiratory Syndrome: Historical, Epidemiologic, and Clinical Features. Infect Dis Clin. 2019;33(4):869-889. https://doi. org/10.1016/j.idc.2019.07.001

12. Calisher $\mathrm{CH}$, Childs JE, Field HE, Holmes KV, Schountz T. Bats: important reservoir hosts of emerging viruses. Clin Microbiol Revs. 2006;19(3):531-45. https://doi. org/10.1128/CMR.00017-06

13. Azhar El, Hui DS, Memish ZA, Drosten C, Zumla A. The
Middle East Respiratory Syndrome (MERS). Infect Dis Clin. 2019;33(4):891-905. https://doi.org/10.1016/j. idc.2019.08.001

14. Rabaan AA, Al-Ahmed SH, Haque S, et al. SARS-CoV-2, SARS-COV, and MERS-COV: A comparative overview. Infez Med. 2020;28(2):174-184.

15. Hui DS, Madani TA, Ntoumi F, Koch R, Dar O. The continuing 2019-nCoV epidemicthreatof novel coronaviruses to global health: the latest 2019 novel coronavirus outbreak in Wuhan, China. Int $J$ Infect Dis. 2020;91:264-6. https://doi.org/10.1016/j. ijid.2020.01.009

16. Murdoch DR, French NP. COVID-19: another infectious disease emerging at the animal-human interface. $N Z$ Med J. 2020;133(1510):12-5.

17. Zhou P, Yang XL, Wang XG, et al. A pneumonia outbreak associated with a new coronavirus of probable bat origin. Nature. 2020;579(7798):270-3..

18. Tai $W, H e ~ L$, Zhang $X$, et al. Characterization of the receptor-binding domain (RBD) of 2019 novel coronavirus: implication for development of RBD protein as a viral attachment inhibitor and vaccine. Cell Mol Immunol. 2020;19:1-8. https://doi.org/10.1038/ s41423-020-0400-4

19. Wong MC, Cregeen SJ, Ajami NJ, Petrosino JF. Evidence of recombination in coronaviruses implicating pangolin origins of nCoV-2019. Biorxiv. 2020. https://doi. org/10.1101/2020.02.07.939207

20. Lam TT, Shum MH, Zhu HC, et al. Identification of 2019-nCoV related coronaviruses in Malayan pangolins in southern China. BioRxiv. 2020. https:// doi.org/10.1101/2020.02.13.945485

21. Wan Y, Shang J, Graham R, Baric RS, Li F. Receptor recognition by the novel coronavirus from Wuhan: an analysis based on decade-long structural studies of SARS coronavirus. J Virol. 2020;94(7). https://doi. org/10.1128/JVI.00127-20

22. Xiao K, Zhai J, Feng, et al. Isolation and Characterization of 2019-nCoV-like Coronavirus from Malayan Pangolins (preprint). Microbiol. 2020. https://doi. org/10.1101/2020.02.17.951335.

23. Liu P, Chen W, Chen JP. Viral Metagenomics Revealed Sendai Virus and Coronavirus Infection of Malayan Pangolins (Manis javanica). Viruses. 2019;11(11):979. https://doi.org/10.3390/v11110979

24. Shi J, Wen Z, Zhong G, et al. Susceptibility of ferrets, cats, dogs, and other domesticated animals to SARS-coronavirus 2. Science. 2020. https://doi. org/10.1101/2020.03.30.015347

25. Liu Z, Xiao X, Wei X, et al. Composition and divergence of coronavirus spike proteins and host ACE2 receptors predict potential intermediate hosts of SARSCoV-2. J Med Virol. 2020;92(6):595-601. https://doi. org/10.1002/jmv. 25726

26. Wan Y, Shang J, Graham R, Baric RS, Li F. Receptor recognition by the novel coronavirus from Wuhan: an analysis based on decade-long structural studies of SARS coronavirus. J Virol. 2020;17:94. https://doi. org/10.1128/JVI.00127-20

27. Shen M, Liu C, Xu R, et al. SARS-CoV-2 Infection of Cats and Dogs?.

28. Gu H, Chu D, Peiris M, Poon LL. Multivariate 
Analyses of Codon Usage of SARS-CoV-2 and other betacoronaviruses. bioRxiv. 2020. https://doi. org/10.1101/2020.02.15.950568

29. Chan JF, Kok KH, Zhu Z, et al. Genomic characterization of the 2019 novel human-pathogenic coronavirus isolated from a patient with atypical pneumonia after visiting Wuhan. Emerg Microbes Infect. 2020;9(1):22136. https://doi.org/10.1080/22221751.2020.1719902

30. Hu B, Ge X, Wang L-F and Shi Z. Bat origin of human coronaviruses. Virol Jl. 2015;12(1):221. https://doi. org/10.1186/s12985-015-0422-1

31. Cui J, Li F and Shi Z-L. Origin and evolution of pathogenic coronaviruses. Nat Rev Microbiol. 2019;17(3):181-92. https://doi.org/10.1038/s41579-018-0118-9

32. Guan $\mathrm{Y}$, Zheng BJ, He YQ, et al. Isolation and characterization of viruses related to the SARS coronavirus from animals in southern China. Science. 2003;302(5643):276-8. https://doi.org/10.1126/ science.1087139

33. Su S, Wong G, Shi W, et al. Epidemiology, genetic recombination, and pathogenesis of coronaviruses. Trends Microbiol. 2016;24(6):490-502. https://doi. org/10.1016/j.tim.2016.03.003

34. Li X, Song $\mathrm{Y}$, Wong $\mathrm{G}$, Cui J. Bat origin of a new human coronavirus: there and back again. Sci China Life Sci. 2020;63(3):461-2. https://doi.org/10.1007/s11427020-1645-7

35. Fung SY, Yuen KS, Ye ZW, Chan CP, Jin DY. A tug-ofwar between severe acute respiratory syndrome coronavirus 2 and host antiviral defence: lessons from other pathogenic viruses. Emerg Microbes Infect. 2020;9(1):558-70. https://doi.org/10.1080/2222175 1.2020 .1736644

36. Zaki AM, Van Boheemen S, Bestebroer TM, Osterhaus $A D$, Fouchier RA. Isolation of a novel coronavirus from a man with pneumonia in Saudi Arabia. N Engl J Med. 2012;367(19):1814-20. https://doi.org/10.1056/ NEJMoa1211721

37. Kandeil A, Gomaa M, Shehata M, et al. Middle East respiratory syndrome coronavirus infection in noncamelid domestic mammals. Emerg Microbes Infect. 2019;8(1):103-8. https://doi.org/10.1080/22221751. 2018.1560235

38. Lau SK, Woo PC, Li KS, et al. Discovery of a novel coronavirus, China Rattus coronavirus HKU24, from Norway rats supports the murine origin of Betacoronavirus 1 and has implications for the ancestor of Betacoronavirus lineage A. J Virol. 2015;89(6):307692. https://doi.org/10.1128/JVI.02420-14

39. Woo PC, Lau SK, Lam CS, et al. Discovery of seven novel Mammalian and avian coronaviruses in the genus deltacoronavirus supports bat coronaviruses as the gene source of alphacoronavirus and betacoronavirus and avian coronaviruses as the gene source of gammacoronavirus and deltacoronavirus. J Virol. 2012;86(7):3995-4008. https://doi.org/10.1128/ JVI.06540-11

40. Ye ZW, Yuan S, Yuen KS, Fung SY, Chan CP, Jin DY. Zoonotic origins of human coronaviruses. Int J Biol Sci.
2020;16(10):1686. https://doi.org/10.7150/ijbs.45472

41. Dhama K, Patel SK, Sharun K, et al. SARS-CoV-2: Jumping the Species Barrier, Lessons from SARS and MERS, Its Zoonotic Spillover, Transmission to Humans, Preventive and Control Measures and Recent Developments to Counter This Pandemic Virus. Preprints. 2020, 2020040011. https://doi. org/10.20944/preprints202004.0011.v1

42. Malik YS, Sircar S, Bhat S, et al. Emerging coronavirus disease (COVID-19), a pandemic public health emergency with animal linkages: Current status update. Indian J Anim Sci. 2020;90(3):(Published Online). https://doi.org/10.20944/preprints202003.0343.v1

43. Tiwari R, Dhama K, Sharun K, et al. COVID-19: Animals, veterinary and zoonotic links. Vet Q. 2020. doi.org/10 $.1080 / 01652176.2020 .1766725$

44. Lorusso A, Calistri P, Petrini A, Savini G, Decaro N. Novel coronavirus (SARS-CoV-2) epidemic: a veterinary perspective. Vet Ital. 2020.

45. Lau SK, Luk HK, Wong AC, et al. Identification of a Novel Betacoronavirus (Merbecovirus) in Amur Hedgehogs from China. Viruses. 2019;11(11):980. https://doi. org/10.3390/v11110980

46. OIE. Questions and Answers on the 2019 Coronavirus Disease (COVID-19), 2020.

47. Sciencealert. Can Pets Get The Coronavirus, And Can We Catch It From Them? Here's The Science https:// www.sciencealert.com/can-you-catch-covid-19-fromyour-pets-here-s-the-science. Accessed on 1st May, 2020.

48. South China morning post. Coronavirus: Hong Kong confirms a second dog is infected, 2020. https://www. scmp.com/news/hong-kong/health-environment/ article/3075993/coronavirus-hong-kong-confirmssecond-dog

49. Dailymail, 2020. https://www.dailymail.co.uk/news/ article-8249461/Four-tigers-three-lions-test-positiveCOVID-19-Bronx-Zoo-bringing-total-8-cats.html.

50. CDC, 2020. https://www.cdc.gov/media/ releases/2020/s0422-covid-19-cats-NYC.html.

51. Deng J, Jin $Y$, Liu $Y$, et al. Serological survey of SARSCoV-2 for experimental, domestic, companion and wild animals excludes intermediate hosts of 35 different species of animals. Transbound and Emerg Dis. 2020. https://doi.org/10.1111/tbed.13577

52. Bonilla-Aldana DK, Dhama K, Rodriguez-Morales AJ. Revisiting the one health approach in the context of COVID-19: a look into the ecology of this emerging disease. Adv Anim Vet Sci. 2020;8(3):234-7. https:// doi.org/10.17582/journal.aavs/2020/8.3.234.237

53. AVMA, COVID-19: FAQs for veterinarians and veterinary clinics, 2020. https://www.avma.org/sites/ default/files/2020-03/covid-19-faq-vet-clinics.pdf Accessed on 1st May, 2020.

54. VinodhKumar OR, Sinha DK and Singh BR. Innovative Technology for Sustainable Development. Chapter 31: Use of Geographic information system (GIS) in Veterinary Science. Editors: Sarju Narain, Sudhir Kumar Rawat Publisher: Biotech Books, New Delhi, 2016. 